\title{
Educación Física Crítica en y desde Latinoamérica
}

\section{Critical Physical Education in and from Latin America}

\section{Educação Física Crítica na e/ou da América Latina}

\author{
AlBerto MORENO DOÑA \\ Escuela de Educación Parvularia. Facultad de Medicina. Universidad de Valparaíso, \\ Chile \\ alberto.moreno@uv.cl \\ ORCID: https://orcid.org/0000-0002-4277-0535
}

FELIPE QUINTÃo DE ALMEIDA

Universidade Federal do Espírito Santo, Brasil

fqalmeida@hotmail.com

ORCID: http://orcid.org/0000-0002-4056-5159

Recibido: 01-07-2021. Aceptado: 15-11-2021.

Cómo citar / Citation: Moreno, A. y Almeida, F. (2021). Educación Física crítica en y desde Latinoamérica, Ágora para la Educación Física y el Deporte, 23, 1-6.

DOI: $\underline{\text { https://doi.org/10.24197/aefd.0.2021.1-6 }}$

\section{A Modo de Presentación}

Pareciera un lugar común asumir, al menos en el contexto de lo que podría denominarse la Educación Física Crítica española, que hablar de pedagogía crítica es hablar de la Escuela de Frankfurt como centro filosófico desde el que se defienden ciertos principios de dicha pedagogía. Se asume que los intereses constitutivos del conocimiento de Habermas (1981) es la justificación de dicha pedagogía en el campo de la $\mathrm{EF}$. Se asume que el planteamiento habermasiano sobre la comunicación en condiciones de simetría (ética del discurso) entre los que argumentan es realmente posible de llevar a la práctica y que ello contribuiría a la construcción de realidades más justas y democráticas. Esta simetría, según Dussel (Aple y Dussel, 2005) es prácticamente imposible pues asume la existencia de una comunidad de comunicación ideal. 
Esta comunidad representa una situación ideal en la cual todos los seres humanos se encuentran en condiciones ideales de habla, tienen las mismas condiciones de vida, los mismos derechos $\mathrm{y}$, por tanto, no existen limitantes que les permitan llegar a consensos. (García, 2011, p.139)

Es esta una situación prácticamente inexistente en muchas partes del mundo, por ejemplo, en Latinoamérica.

La mayor limitación que encontramos en esta lógica propuesta está relacionada con la imposibilidad de legitimación discursiva de los miembros de una comunidad cuando la realidad del sistema mundo está estructurada en función del ser hombre, europeo-norteamericano, blanco, heterosexual, capitalista y patriarcal (Dussel, 2015; Grosfoguel, 2013). Es por ello que asumimos que la complejidad del conocimiento (McLaren y Kincheloe, 2008) en los incios del siglo XXI no está siendo abordada en los medios de producción científica de carácter tradicional.

Es desde aquí que lo obvio (ob: hacia; vio: camino) no permite visualizar otras lógicas epistemológicas desde la que abordar la pedagogía crítica $\mathrm{y}$, por tanto, ser conscientes de la importancia de visibilizar otras realidades desde las que pensar(se) el mundo. La colonialidad del poder (Quijano, 2000) termina valorando, aceptando y legitimando un conocimiento anclado aún en una lógica dualista en términos de civilización y barbarie (Dussel, 2015) y en la que los que viven en situación de pobreza, los otros géneros y las etnias, son vistos como una forma de subhumanidad, "una forma degradada de ser que combina cinco formas de degradación: ser ignorante, inferior, atrasado, vernáculo o folklórico y perezoso e improductivo" (De Sousa Santos, 2014: s/p).

Asumimos que la primera condición de lo crítico es la ética que orienta y define los horizontes de sentido del quehacer pedagógico. A nuestro parecer, y siguiendo a Dussel (2016), la ética es la crítica primera, y toda ética surge en la emergencia del otro y de lo otro, de la proximidad relacional que es posible levantar desde la dignidad de un ser vivo sustantivamente diferente. Dicha proximidad implica el reconocimiento de que la diferencia no es sólo de apariencia (óntica) sino también de sentidos de ser (ontológica). Ello implica, como consecuencia, el reconocer el lugar del propio mundo y del mundo del otro. Pero el otro se expresa desde ese mundo que le da sentido a su existir y no desde unas categorías universales (propias de la ciencia de 
carácter más tradicional) que no le son propias sino impuestas (Dussel, 2016).

Es por lo anterior que este monográfico "Educación Física Crítica en y desde Latinoamérica" está realizado desde aquellos que habitan dicho territorio. Son sus voces, sus propuestas, análisis y posicionamientos los que se reflejan en las producciones diversas que el lector podrá encontrar. Y desde allí se muestra la complejidad de eso que llamamos pedagogía crítica en y desde un contexto que habita constantemente en la exclusión. Y que ha sido y es constantemente excluido de esos círculos de poder tan cerrados sobre sí mismos y tan propios de la ciencia de carácter eurocéntrico.

Colombia, Venezuela, Chile, Argentina, Uruguay y Brasil son los espacios geográficos y los tiempos académicos y profesionales desde los que se construye este monográfico. No conforman una realidad homogénea desde la que pensar la educación física crítica, pero sí muestran las diversidades epistemológicas, teóricas, sociales y científicas desde la que es posible cierta relación intercultural para comprender eso que llamamos pedagogía y educación física.

En el primer artículo, Alejo Levoratti, a través del análisis de documentos, trayectorias y redes académicas, da cuenta de los procesos de construcción de la actual propuesta conceptual de la Educación Física en el diseño curricular de la formación docente inicial en la provincia de Buenos Aires. El autor va mostrando las discusiones y posicionamientos disciplinares que se ponen en tensión desde aquellos que han participado (funcionarios y personal técnico) en la construcción de dicho diseño, además de ir desvelando los procesos de crítica que se fueron generando en Argentina en la interface entre Educación Física, Ciencias Sociales y Ciencias de la Educación.

El segundo trabajo, a cargo de Alixon Reyes Rodríguez, se muestra el caso de la Educación Física en Venezuela. Después de dar cuenta de cómo la Educación Física venezolana ha pasado por la reproducción de ciertas tendencias conservadoras, se señala el quiebre histórico que va determinando la aparición de nuevas sensibilidades desde las que la EF comienza a preocuparse de las desigualdades sociales y las consecuencias que ellas han ido originando.

Raumar Rodríguez Giménez y Cecilia Seré Quintero, en el tercer artículo, indagan sobre la conformación de una perspectiva pedagógica crítica en la educación física, el deporte y la recreación en Uruguay. Y lo hacen desde el análisis de las publicaciones mensuales de la Revista 
Revista Nexo Sport entre 1983 y 1990. Ello les permite identificar tres grandes momentos, a saber: a) reivindicación del carácter pedagógico de la educación física; b) recepción del movimiento brasilero Deporte Para Todos y cómo este influyó en las prácticas tradicionales de las prácticas deportivas; y c) emergencia de la recreación como campo específico de cuestionamiento de las condiciones culturales, políticas, económicas y sociales del momento.

El cuarto trabajo está escrito por Bastián Carter Thuillier, Víctor López Pastor, Francisco Gallardo Fuentes y Juan Carter Beltrán. Los autores analizan, críticamente, las posibilidades de la EF como facilitadora de procesos de inclusión en contextos escolares con presencia de niños y niñas migrantes en Chile. Se plantea la necesidad de consolidar ambientes educativos interculturales desde los que se incentive, permita y legitime la coexistencia de las diversas identidades.

Eduardo Galak, Ivan Marcelo Gomes y Fabio Zoboli, en el quinto trabajo, analizan los procesos de construcción de conocimiento y los diversos posicionamientos epistemológicos en relación a la crítica a los modelos pedagógicos de la Educación Física en Brasil y en Argentina. Y lo hacen a través del análisis de material empírico obtenido de los dos grandes congresos del campo de la EF en Latinoamérica: el Congresso Brasileiro de Ciências do Esporte (CONBRACE) y el Congreso Argentino de Educación Física y Ciencias (CEF\&C).

En el sexto artículo, Felipe Quintão de Almeida reflexiona acerca de las condiciones de posibilidad de una pedagogía crítica en EF en Latinoamérica. Para ello describe diversas experiencias críticas en el campo de la EF llevadas a cabo en Brasil, Argentina, Colombia, Uruguay y Chile. Propone la necesidad de hacer dialogar las propuestas críticas latinoamericanas con las de otras latitudes.

Seguidamente, Karen Lorena Gil Eusse analiza la relación entre el movimiento crítico de la EF colombiana y sus implicaciones para una pedagogía crítica del campo. Específicamente se discute el hecho de que la renovación discursiva que resultó de la crítica a la tradición deportivista del campo no llegó a manifestarse en propuestas de pedagogías críticas.

Marco Fidel Gómez Londoño, Adriana Salazar Hurtado, Juan Carlos Echavarría y Sandra Maryory Pulido, trabajan la relación entre la cultura académica y la práctica pedagógica del profesorado en formación de Educación Física para el reconocimiento de las condiciones de existencia en la sociedad del conocimiento. Desde una metodología cualitativa se va 
mostrando cómo existe una práctica pedagógica sometida a las lógicas escolares que resta autonomía al profesorado que se encuentra en proceso de formación.

William Moreno Gómez, Paola Andrea Acevedo Carmona y Estefanía Pérez Sánchez construyen un texto resultado de una investigación centrada en las condiciones sociales en las que se desarrolla la formación del profesorado del campo de la EF, el Deporte y la Actividad Física y Salud en Medellín, Colombia. Se analiza cómo la formación está condicionada por las demandas de la sociedad del conocimiento y las de una sociedad que vive en constante conflicto,

En el penúltimo artículo, Alberto Moreno Doña y Sergio Toro Arévalo presentan una crítica al sistema educativo chileno y latinoamericano desde los conceptos de neoliberalismo y modernidad como proyecto civilizatorio centrado en la negación de las otredades. A partir de ahí justifican la imposibilidad de una Educación Física que, en tanto física, separa, excluye y niega las diversas formas de vivir. Terminan proponiendo la motricidad humana como una alternativa ontológica y epistemológica, entendida como la capacidad-condición de hacer-se mundo, desde la que es posible pensar lo educativo.

En el último trabajo, Carolina Poblete Gálvez tensiona dos realidades socioculturales educativas que enmarcan la educación chilena. Por un lado, el reconocimiento de que todo lo chileno está impregnado de un desarraigo del mapuche a partir de una construcción blanqueada y racista de la conformación de la sociedad chilena $\mathrm{y}$, por otro, cierto homenaje al saber eurocéntrico. La autora plantea que ambos aspectos revelan las contradicciones y limitaciones de la circulación de un conocimiento ancestral, como es la práctica física del palín en las clases de educación física.

Como editores de este monográfico, y en nombre de los autores y autoras de los distintos trabajos que lo componen, queremos agradecer a la revista Ágora para la Educación Física y el Deporte el habernos proporcionado este espacio para mostrar nuestras experiencias y saberes sobre la Educación Física Crítica en y desde Latinoamérica.

\section{BIBLIOGRAFÍA}

Aple, K., y Dussel, E. (2005). Ética del discurso y ética de la liberación. Madrid: Trotta. 
De Sousa Santos, B. (2014). La gran división. Diario el Mundo, 13 noviembre. Ver en https://www.pagina12.com.ar/diario/elmundo/4-259727-2014-11$\underline{13 . h t m l}$

Dussel, E. (2015). Filosofías del sur. Descolonización y transmodernidad. Madrid: Akal.

Dussel, E. (2016). 14 Tesis de etica. Hacia la esencia del pensamiento critico. Madrid: Trotta.

García, N. (2011). Reseña de Apel, K. O., y Dussel, E. D. (2005). Ética del discurso y ética de la liberación. Madrid: Trotta. En Versiones (2 $2^{\mathrm{a}}$ época), 1, 137-148. Disponible en:

https://revistas.udea.edu.co/index.php/versiones/article/view/11043/10114

Grosfoeguel, R. (2013). Racismo/Sexismo epistémico, universidades occidentalizadas y los cuatro genocidios/epistemicidios del largo siglo XVI. Tabula Rasa, 19, 31-58.

Habermas, J. (1981). Conocimiento e Interés. Madrid: Taurus.

McLaren, P., y Kincheloe, J. (2008) [Eds.]. Pedagogía críica. De qué hablamos, dónde estamos. Barcelona: Graó.

Quijano, A. (2000). Colonialidad del poder, eurocentrismo y América Latina, En E. Lander (comp.) La colonialidad del saber: eurocentrismo y ciencias sociales. Perspectivas Latinoamericanas (pp. 201-246). Buenos Aires: CLACSO. 